\title{
¿Ante el primer diccionario monolingüe judeoespañol?
}

\author{
Aitor García Moreno** \\ ILC-CCHS, CSIC, Madrid
}

El presente artículo se dedica a estudiar las 131 entradas del vocabulario contenido en el texto sefardí El catecismo menor, traducido del inglés y publicado (Constantinopla, 1854) por la misión protestante escocesa de Alexander Thomson. En él, junto con la aclaración de formas en el contexto doctrinal del catecismo, encontramos no pocos casos en que la explicación dada en judeoespañol bien podría corresponder a la definición de cualquier diccionario al uso de la época.

Palabras Clave: Judeoespañol; literatura sefardí; catecismos protestantes; diccionarios; lexicografía; misioneros; Alexander Thomson; Free Church of Scotland; Imperio otomano.

The First Judeo-Spanish Monolingual Dictionary?.- In this article we study the 131-entries vocabulary contained in the Sephardic text El Catecismo Menor, translated from English and published (Constantinople, 1854) by the Scottish Protestant mission led by Alexander Thomson. In it, along with the clarification of doctrinal concepts, we find several cases where the explanation given in Judeo-Spanish could correspond to any dictionary definition of the use at the time.

Keywords: Judeo-Spanish; Sephardic Literature; Protestant Catechisms; Dictionaries; Lexicography; Missioners; Alexander Thomson; Free Church of Scotland; Ottoman Empire.

* El presente artículo se ha elaborado en el marco de los Proyectos de Investigación consecutivos denominados «Sefarad, siglo XXI (2009-2011): Edición y Estudio Filológico de Textos Sefardíes» (FF2009-10672 [subprograma FILO]) y «Sefarad, siglo XXI (20132014): Edición y Estudio Filológico de Textos Sefardíes» (FFI2012-31390).

**a aitor.garcia@cchs.csic.es 
Tal y como recoge Elena Romero (1992), el establecimiento en el Imperio otomano a mediados del siglo XIX de una serie de misiones protestantes con la conversión de los judíos sefardíes como objetivo, dio como resultado -más allá de sus logros misioneros'- la publicación (principalmente en Constantinopla y Esmirna) de un importante número de textos judeoespañoles aljamiados de diversa índole: distintas traducciones de la Biblia (pp. 43-44) o de alguno de sus libros como Salmos (p. 59); varias versiones del Nuevo Testamento (p. 60); algún que otro oracional cristiano (pág. 49); un texto sobre la pascua judía (p. 68); libros de polémica (p. 134); la revista El Manadero (p. 182), y una serie de obras de carácter pedagógico, incluyendo un importante diccionario de hebreo bíblico (pp. 200-201).

El texto que nos ocupa lleva por título El catecismo menor, o una corta declaración de lo que creen los protestantes cristianos, con las prebas menesterośas ['necesarias'] dadas de largo, tanto del Arba'á ve'esrim ['la Biblia'] como del Nuevo Testamiento. Trasladado del inglés [...] $]^{2}, \mathrm{y}$

\footnotetext{
${ }^{1}$ Aunque no contamos con demasiados datos concretos sobre el éxito de estas misiones (vid. Bornstein-MAKOVETSKY 2002: 104-112), la propia Elena RoMERo (1992: 134) señala que debieron obtener algún fruto, a tenor de la leyenda «para el uśo de las escolas y famillas de los yisraelitas protestantes» que se encuentra en los textos más tardíos. Entre los sefardíes convertidos destaca la figura de J̀osef Romano, activo periodista de Esmirna, redactor de La yoź del pueblo (Romero 2010: 445-446, nt. 13), que tal vez se esconda bajo el «28-year-old businessman, described as an educated man», convertido en Esmirna por la misión escocesa en 1887, que recoge BoRnSteIN-MAKOVETSKY (2002: 126, núm. 126). Para una amplia lista de fuentes bibliográficas en las que se recogen datos sobre las vicisitudes de la labor de estas misiones, vid. BornsteIn-MAKOVETSKY 1996: 307-310. Especialmente útiles para nuestro estudio son los Proceedings of the General Assembly of the Free Church of Scotland de 1854 y 1855.

${ }^{2}$ Corresponde a la cita bíblica $\ll_{6} \mathrm{Y}$ estas palabras que yo te encomendo hoy, estarán sobre tu corazón; ${ }_{7}$ l las meldarás a tus hijos, y hablarás de ellas en tu estar en tu casa y en tu andar en la carrera, y en tu yacer y en tu levantar» (Debarim [= Deuteronomio] 6, 6-7). La traducción judeoespañola parece responsabilidad del autor del Catecismo, por cuanto no coincide exactamente con la de ninguna otra Biblia española o sefardí anterior conocidas. Para la presentación de ejemplos en judeoespañol, sigo en lo fundamental el sistema de la Escuela Española de Filología Sefardí expuesto en Hassán (1978), con las ligeras enmiendas propuestas en GarCía Moreno (2004: 31-33), recordando que la distribución en nuestra edición de <-r-> y <-rr-> intervocálicas sigue las reglas de la ortografía normativa del español estándar, independientemente de que la aljamía ofrezca siempre una sola reš, en paralelo a nuestro proceder en la distribución de $<\mathrm{s}>,<\mathrm{c}>\mathrm{y}<\mathrm{z}>$ según los casos.
} 
apareció sin autor en «Constantinopla, en la emprimería ['imprenta'] de Sr. A. B. Chúrchil, 1854-5615»³.

Pero no es su contenido doctrinal el que nos interesará, sino el hecho de contener lo que podríamos considerar como el primer diccionario monolingüe judeoespañol ${ }^{4}$.

\section{El CATECISMO MENOR}

Como tantos otros textos sefardíes publicados por la misión escocesa, El catecismo menor (abrev. Catecismo) es obra del Rev. Alexander Thomson ${ }^{5}$, activo traductor, responsable de la versión judeoespañola de la Biblia publicada en Constantinopla en 1873, y de varios de los libros de carácter pedagógico antes aludidos. Así se recoge en Proceedings (1855: 76):

The production of Mr. Thomson's pen in Hebrew-Spanish ${ }^{6}$, which have been laid on the table of the Assembly from time to time as they appeared, suffice to shew [sic] that nothing that could either reach the mind or attract the taste of the Jews among whom he labours has been thought too much labour to produce. The works issued during the past year are the following: (1) A translation of Dr.

\footnotetext{
${ }^{3}$ Consulto el ejemplar de la Biblioteca del Museo Sefardí de Toledo, disponible en http://bvpb.mcu.es/museos/es/consulta/registro.cmd?id=442051.

${ }^{4}$ Para mayor información sobre textos sefardíes anteriores que, en mayor o menor medida, tienen contenido lexicográfico, véanse los trabajos de KoHRING (2011: 303-315 y 349) y Bunis (2011: 353-360). Destacan entre todos ellos, de una parte, el Séfer Osar hahayim (Viena, 1823) de Yisrael Bajar Hayim, pues en el vocabulario trilingüe hebreojudeoespañol-alemán que contiene podemos encontrar algunas pseudodefiniciones en judeoespañol, según ha mostrado Quintana (2013: 44); y, de otra, el Cuntrés darjé nó am (Belgrado, 1839), estudiado por Bunis (2002).

${ }^{5}$ Thomson nació en Arbroath (Escocia) el 2 de diciembre de 1820. Después de cursar estudios en St. Andrew's University, inició su trabajo como misionero en 1845 y, tras un año de preparación en Budapest, fue enviado a Turquía en 1846 por la Free Church of Scotland. En 1860 se convirtió en agente de la British and Foreign Bible Society para el Levante, cargo que desempeñó hasta su muerte el 15 de enero de 1899 (Missionary Review 1899: 320).

${ }^{6}$ Tal es la denominación que encontramos en muchos de los boletines y publicaciones periódicas de las iglesias protestantes del momento, para referirse al idioma de los sefardíes. En Bliss (1904: 649), en el artículo referido a Schauffler, W. G. leemos: «... He translated the Bible into Hebrew-Spanish, that is, Spanish with a mixture of Hebrew words and written with Hebrew characters».
} 
Barth's "Bible Stories", with a great number of woodcut illustrations, similar to the "Escalera" or "Ladder" noticed in last Report". (2) The Shorter Catechism, with the Scripture proofs printed in full -a work on which great pains have been bestowed-Old Testament proofs for every statement, as well as proofs from the New Testament, being furnished. (3) "The Martyrs of Madgascar [sic]", with woodcut illustrations. (4) "The Diamond Bracelet", in the same style";

donde a continuación se señala que en su realización, Thomson fue ayudado por Alexander Tomory, un converso de origen húngaro ${ }^{10}$ :

During a considerable period Mr Thomson was assisted in his literary labours by $\mathrm{Mr}$ Tomory, one of the first fruits of the work at Pesth, whose services are highly steemed both by the missionaries there and the Committee at home.

El Catecismo consta de 84 páginas y está escrito en aljamía hebrea con caracteres raší, salvo en los títulos de cada sección en que se utilizan caracteres cuadrados (merubá). Tras la «Tabla de contenidos» (pp. 2-4), presenta (pp. 5-77) la traducción ajustada de las 107 preguntas y respuestas del Westminster Shorter Catechism (1 ${ }^{\mathrm{a}}$ ed. 1647); y le siguen, hasta el final del libro, otra serie de textos: «Los diez mandamientos» (pp. 77-78); «La oración del Señor» ${ }^{11}$ (p. 79); «El Credo, o corta suma de la creencia cristiana» (p. 79); una «Oración antes de comer» (p. 80); un

\footnotetext{
${ }^{7}$ Entendemos que se refiere al libro Ele toledot bené Yisrael o Cincuenta y dos cuentos tirados del Arba'áve'esrim para el uso de escuelas y familias, con grabados /Trasladado del alemán con adiciones (Constantinopla: A. B. Chúrchil, 1854), que vio una edición ampliada posterior titulada Ele toledot bené Yisrael: quiere dećir ciento y dieź y siete cuentos tirados del Arba á ve'esrim y de las historias antiguas para el uśo de los yisraelitas protestantes, compuesto por Alexánder Tomson (Constantinopla: A. H. Boyaĝian, 1886).

${ }^{8}$ Se trata de La escalera a la anveźadura (para los niños y las niñas) (Constantinopla, 1853 y, con el añadido del título, Constantinopla, ca. 1880) -libro que en 1888 tuvo una edición ampliada titulada La escalera o Lecciones progresivas en la cencia y literatura (Romero 1992: 221). Con motivo de su aparición, leemos en Proceedings (1854: 116): «The last production of Mr. Thomson's pen will probably be the most useful, as it certainly is the most interesting. It is entitled the "Escalera", or "Ladder", being a collection in the Hebrew-Spanish language, of prose and poetry on a great variety of subjects».

${ }^{9}$ Ignoramos cuáles sean estos dos textos, ni si realmente corresponden a traducciones al judeoespañol.

${ }^{10}$ El dato sobre Tomory lo recoge también Bornstein-MAKOvETSKy (2002: 106).

${ }^{11}$ Es decir, The Lord's Prayer, título inglés del Padre Nuestro.
} 
«Hacimiento ['Acción'] de gracias después de comer» (p. 80); «Algunas oraciones para los jóvenes: Oración para la mañana» (pp. 80-81); «Otra oración para la mañana» (pp. 81-82); «Oración para la tarde» (pp. 82-83), y termina con «Otra oración para la tarde» (pp. 83-84).

La estructura interna de esa amplia sección que contiene las preguntas y respuestas del catecismo en sí -como en el general de las obras didácticas de la época, basadas en las figuras dialógicas de la retórica clásica- es la siguiente: se presenta numerada $a$ ) la pregunta; se da $b$ ) la respuesta; y se aducen $c$ ) una serie de pruebas, tomadas de las Sagradas Escrituras (Antiguo y Nuevo Testamento), referidas a distintos elementos de la doctrina contenidos en la respuesta. A dichos elementos -que presentan una especie de llamada de nota consistente en un número entre paréntesis como se verá infra en la edición crítica-, le pueden corresponder una o más citas.

La novedad del Catecismo -y el hecho que nos lleva a estudiarlo aquí- consiste en que, en 64 ocasiones, tras la respuesta y antes de la reseña de citas con las pruebas, se introduce en cuerpo menor una especie de vocabulario que busca aclarar determinados términos o expresiones usados en las respuestas. Estas breves listas de palabras pueden contener desde sólo una entrada (lo que sucede 26 veces), hasta seis (como en el caso de la pregunta 92).

Esta particularidad parece inspirada en los catecismos para niños del Dr. Isaac Watts (1674-1748). Así, en el tercero de ellos, titulado The Assembly's Catechism with Notes, or the Shorter Catechism composed by the Assembly of Divines at Westminster: with A brief Explication of the more difficult Words and Phrases contained in it, for the Instruction of Youth en la edición que manejamos (1745), aunque no se aducen pruebas de las Sagradas Escrituras, tras muchas de las respuestas se presenta la aclaración de un puñado de voces tal y como anuncia en el prefacio: «with the more difficult Words explained after each answer» (p. 7).

\subsection{El vocabulario}

El número total de entradas en los distintos vocabularios o miniglosarios que siguen a la mayoría de las respuestas del Catecismo es de 131, pero hay que tener en cuenta que la palabra gracia se explica tres 
veces, y que en ocasiones encontramos dos formas de un mismo verbo (convencer y convenciéndonos, y recibamos y recibimos). Ordenadas alfabéticamente - por el primer sustantivo en el caso de formas complejasy con la reseña en subíndice del número de la pregunta/respuesta a la que siguen, $\operatorname{son}^{12}$ :

\begin{tabular}{|c|c|c|}
\hline aḅajamiento $_{23}$ & corporal y carnal $_{96}$ & fieles $_{37}$ \\
\hline & criaturas, las $\sim_{10}$ & fin $_{1}$ \\
\hline abssueltos $_{38}$ & derecho $_{34}$ & firmamiento $_{12}$ \\
\hline aḅuso $_{55}$ & descubierta $_{39}$ & folor $_{84}$ \\
\hline administra $_{91}$ & descuidadośo $_{61}$ & gracia $_{20,36,86}$ \\
\hline afalagar $_{25}$ & descuido $_{65}$ & grados $_{64}$ \\
\hline agradecido $_{98}$ & desreglados $_{81}$ & guardemos $_{50}$ \\
\hline $\operatorname{agravamientos}_{83}$ & devdas $_{105}$ & hacienda $_{74}$ \\
\hline juntamiento 19 & devdores, nuestros $\sim_{105}$ & hecho $_{33}$ \\
\hline nén 107 & dicernir $_{97}$ & hombre, el $\sim$ entero $_{3}$ \\
\hline olicación 29 & dilig̀gencia $_{90}$ & iglesia $_{95}$ \\
\hline plicados 92 & dilig̀ente $_{85}$ & imág̀enes $_{51}$ \\
\hline tributos ${ }_{54}$ & DiO $_{44}$ & imputada a nós $_{33}$ \\
\hline ribuyuéndole 107 & disminuye $_{75}$ & inferiores $_{64}$ \\
\hline enefic10 32 & eficiente $_{29}$ & infinito $_{4}$ \\
\hline sora 31 & endereźar ${ }_{99}$ & injustamente $_{69}$ \\
\hline $10_{52}$ & enšalžamiento $_{23}$ & inmudable $_{4}$ \\
\hline nformidad & esforźados $_{105}$ & intentando $_{87}$ \\
\hline ntento & esfuerźos $_{68}$ & justos $_{33}$ \\
\hline nvencer & espiritual $_{96}$ & libra $_{53}$ \\
\hline nvenciéndonos & esteriores $_{85}$ & libre $_{33}$ \\
\hline nvertir ${ }_{89}$ & esṿiblamiento $_{55}$ & libremente $_{31}$ \\
\hline raźón, con & eternidad $_{38}$ & licenciado $_{68}$ \\
\hline cumplido $_{87}$ & eterno $_{4}$ & llamada $_{30}$ \\
\hline
\end{tabular}

${ }^{12}$ Advertimos en este punto que, como se verá en la siguiente lista y se estudia más adelante (vid. apdo. 3.1.) el texto presenta particularidades que lo alejan de la norma gráfica judeoespañola del momento. 


\begin{tabular}{|c|c|c|}
\hline maldición $_{84}$ & principal $_{1}$ & representados $_{92}$ \\
\hline manifiesta, se $\sim{ }_{96}$ & privileg̀ios $_{34}$ & sacramento $_{92}$ \\
\hline mantengamos $_{50}$ & propiedad $_{52}$ & salvación $_{20}$ \\
\hline Mašíaḥ $_{21}$ & prosperidad $_{66}$ & salvante $_{86}$ \\
\hline medios $_{85}$ & providencia $_{8}$ & santificar $_{60}$ \\
\hline merecidos $_{96}$ & quebrantamiento $_{14}$ & sellados $_{92}$ \\
\hline metimiento $_{94}$ & raźones $_{52}$ & semanal $_{59}$ \\
\hline moral $_{40}$ & recibamos $_{50}$ & sensibles $_{92}$ \\
\hline mundanos $_{60}$ & recibimos $_{86}$ & sentimiento, verdadero $\sim{ }_{87}$ \\
\hline necesarias $_{60}$ & reconocidos $_{38}$ & señales $_{92}$ \\
\hline nombre $_{54}$ & reconocimiento $_{98}$ & Señor $_{44}$ \\
\hline nota $_{48}$ & regmidor $_{20}$ & soberanidad $_{52}$ \\
\hline obra $_{35}$ & reino, el $\sim$ de la gracia ${ }_{102}$ & superiores $_{64}$ \\
\hline omisión $_{61}$ & reino, el $\sim$ de la honra & título $_{54}$ \\
\hline ordenanźa $_{50}$ & 102 & vanidad, a la $\sim_{53}$ \\
\hline participación $_{94}$ & reino, el de Satán ${ }_{102}$ & virtud $_{91}$ \\
\hline perjudicial $_{78}$ & relaciones $_{64}$ & visible $_{95}$ \\
\hline preba $_{106}$ & renovando $_{31}$ & Yešúa' $_{21}$ \\
\hline prefación $_{43}$ & reposamos, nos $\sim_{86}$ & \\
\hline
\end{tabular}

Cabe señalar que en el catecismo de Watts (1745) en el que entendemos que se inspiró Alexander Thomson, se explican ya más de la mitad de las palabras de nuestra lista, tras las mismas respuestas; y aunque la explicación dada por Thomson en judeoespañol no responda a la traducción de la explicación de Watts en inglés, creemos que la selección de éstas sí vino inducida por aquéllas.

Las correspondencias son ${ }^{13}$ :

${ }^{13}$ Presentamos a dos columnas las formas del Catecismo (izda. en redonda) y de WATTS (1745) (dcha. en cursiva), sin incluir el número de respuestas en que aparecen, por haber sido ya consignado en la lista anterior y dado que coincide en ambos textos: sólo en el caso de fieles (resp. 37 del Catecismo), el equivalente believers aparece explicado en Watts (1745) tras la siguiente respuesta (38). En cuanto a la forma gracia que -como decíamos-, en el Catecismo se explica tres veces, sólo se da coincidencia con el texto de Watts tras la resp. 86. Asimismo, en ocasiones, lo que en Watts (1745) aparece 


\begin{tabular}{|c|c|}
\hline Catecismo & Watts 1745 \\
\hline aḅajamiento & Humiliation \\
\hline aḅraźar & Embrace... \\
\hline aḅsueltos & Acquitted \\
\hline aḅuso & Profaning and abusing \\
\hline administra & Administer \\
\hline afalagar & Reconcile \\
\hline agravamientos & Aggravation \\
\hline ajuntamiento & Communion with God \\
\hline amén & Amen \\
\hline aplicación & Effectual application... \\
\hline aplicados & Applied \\
\hline atributos & Attributes \\
\hline beneficio & Benefits \\
\hline besorá & Gospel \\
\hline ćelo & Zeal \\
\hline conciencia & Conscience \\
\hline conformidad & Conformity to the law \\
\hline contento & Contentment \\
\hline convencer & To convince sinners \\
\hline convenciéndonos & To convince us \\
\hline convertir & To convert sinners \\
\hline corporal y carnal & Corporal \\
\hline descuido & Neglecting... \\
\hline desreglados & Inordinate... \\
\hline dicernir & To discern... \\
\hline eficiente & Effectual application... \\
\hline enšalžamiento & Exaltation \\
\hline espiritual & Spiritual... \\
\hline
\end{tabular}

como un solo (y largo) lema, en el Catecismo se desdobla; así sucede con: chief end $\sim$ fin y principal (1); effectual application aplicación y eficiente (29); profaning and abusing $\sim$ esyiblamiento y aḅuso (55); saving grace $\sim$ gracia y salvante (86); sensible signs $\sim$ señales y sensibles (92), y visible church $\sim$ iglesia y visible (95). En estos casos, el equivalente en la columna de WATTS (1745) aparecerá repetido. 


\begin{tabular}{|c|c|}
\hline Catecismo & Watts 1745 \\
\hline esṿiblamiento & Profaning and abusing \\
\hline eternidad & To all eternity \\
\hline eterno & Eternal \\
\hline fieles & Believers \\
\hline fin & Chief end \\
\hline gracia & Saving grace \\
\hline hombre, el entero & Whole man \\
\hline iglesia & Visible church \\
\hline imág̀enes & Images \\
\hline imputada a nós & Imputed to us \\
\hline inferiores & Inferiors \\
\hline infinito & Infinite \\
\hline inĵustamente & Unjustly \\
\hline libre & Free grace \\
\hline maldición & Curse \\
\hline Mašíạ̣ & Christ \\
\hline metimiento & Ingrafting into Christ \\
\hline moral & Moral law \\
\hline necesarias & Works of necessity \\
\hline nombre & Names of God \\
\hline omisión & Omission \\
\hline ordenanźa & Ordinances \\
\hline perĵudicial & Prejudicial, injurious \\
\hline prefación & Preface \\
\hline principal & Chief end \\
\hline propiedad & Propriety \\
\hline prosperidad & Prosperity \\
\hline quebrantamiento & Transgression of the law \\
\hline reconocidos & Acknowledged \\
\hline regmidor & Redeemer \\
\hline reino, el $\sim$ de la gracia & Kingdom of grace \\
\hline reino, el $\sim$ de la honra & Kingdom of glory \\
\hline reino, el de Satán & Satan's kingdom \\
\hline
\end{tabular}




\begin{tabular}{|l|l|}
\hline \multicolumn{1}{|c|}{ Catecismo } & \multicolumn{1}{c|}{ Watts 1745 } \\
\hline renovando & Renewing our wills \\
\hline representados & Represented \\
\hline salvación & Salvation \\
\hline salvante & Saving grace \\
\hline santificar & Sanctified \\
\hline sellados & Sealed \\
\hline sensibles & Sensible signs \\
\hline señales & Sensible signs \\
\hline soberanidad & Sovereignty \\
\hline superiores & Superiors \\
\hline título & Titles of God \\
\hline vanidad, a la $~$ & .. in vain \\
\hline virtud & Virtud \\
\hline visible & Visible church \\
\hline Yešúa & Jesus \\
\hline
\end{tabular}

\section{EDICIÓN CRÍTICA PARCIAL}

En las próximas páginas presentamos la edición crítica anotada del texto de aquellas preguntas y respuestas -sin sus pruebas- que van seguidas de glosario en el Catecismo. El número de página del original se señala en superíndice entre corchetes y se introduce la marca ${ }^{[\ldots . .]}$, también volada, para señalar aquella porción de texto no incluida en nuestra edición, cuando no ha habido cambio de página. Marcamos en cursiva (nuestra) aquellos segmentos de las respuestas que se aclaran en el glosario subsiguiente, y presentamos sangradas y en negrita -como en el original- las entradas de este. Las abreviaturas se desarrollan (entre corchetes) únicamente la primera vez que aparecen.

${ }^{[p . ~ 5]}$ Pregunta 1. ¿Cuál es el principal fin ${ }^{14}$ para el cual el hombre fue hecho?

${ }^{14}$ La anteposición del adjetivo al sustantivo que apreciamos en este y otros muchos ejemplos responde -a nuestro juicio- al seguidismo del original inglés que se traduce; $\mathrm{cf}$. ing. chief end. 
Respuesta. El principal fin para el cual el hombre fue hecho es honrar a Dio (1), y goźarse en Él para siempre (2).

principal $=$ el más importante.

fin = una cosa bušcada y deseada.

[p. 7] Pre[gunta]. 4. ¿Qué cosa es Dio?

Res[puesta]. Dio es espíritu (1) infinito (2), eterno (3) y inmudable (4) en su ser (5), en su sabiduría (6), su poder (7), su santidad (8), su justedad (9), su bondad (10) y su verdad (11).

infinito $=\sin$ fin o término.

eterno $=$ sin principio ni cabo.

inmudable $=$ que no se puede demudar.

${ }^{[p . ~}{ }^{10]}$ Pre. 8. ¿Cómo cumple Dio sus fueros?

Res. Dio cumple sus fueros en las obras de la Creación (1) y de la Providen$\operatorname{cia}(2)$.

providencia $=$ la potencia de ver de avante ['con anterioridad'] lo que acontecerá; goberno, reg̀imiento.

${ }^{[\ldots . .]}$ Pre. 10. ¿Cómo creó ${ }^{15}$ Dio al hombre?

Res. Dio creó al hombre macho y hembra según su propia semejanźa (1) en sabiduría, derechedad y santidad (2), con poder sobre las ${ }^{\left[{ }^{11]}\right.}$ criaturas (3).

las criaturas $=$ todas las cosas yivas.

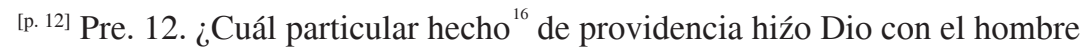
en el estado en el cual fue creado?

Res. Dio, habiendo creado al hombre, entró con él en un firmamiento de

${ }^{15}$ Como veremos también en otros casos, es imposible determinar si la vocalización de la forma pel original es crió - como es habitual en judeoespañol- o creó-sobre el modelo hispánico-. Optamos por esta última, dado el alto nivel de hispanización que ofrece el texto.

${ }^{16}$ Vid. nota 14; cf. ing. special act. 
vida, demandando de él cumplida obediencia ${ }^{17}$ (1) y vedándolo de comer del árbol del saber bien y mal con pena de muerte (2).

firmamiento $=$ trato entre dos o más personas.

${ }^{[\ldots .]}$ Pre. 14. ¿Qué cosa es el pecado?

Res. El pecado es toda mengua de conformidad a la Ley de Dio, o todo quebrantamiento ${ }^{[\mathrm{p} .13]}$ de aquella Ley (1).

conformidad = semejanza, obediencia.

quebrantamiento $=$ desobediencia, rebello.

${ }^{[p .}{ }^{15]}$ Pre. 19. ¿Cuál es el estado de angustia en el cual cayó el hombre?

Res. Por su caída perdieron todos los hombres el ajuntamiento con Dio (1); están debajo del folor ['furor, ira'] y de la maldición de Él (2), y ansí quedan sujeftados a todas las angustias de esta vida, a la muerte miśma y a las penas de guehinam ['el infierno'] para siempre (3).

â̂untamiento $=$ compaña, amistad.

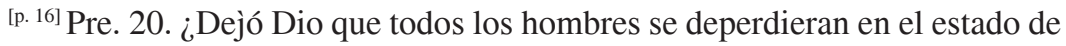
pecado y de angustia?

Res. Dio, habiendo de su libre veluntad sola escog̀ido algunos desde siempre para la vida eterna (1), entró en un firmamiento de gracia para escaparlos del estado de pecado y de angustia, y para traerlos en un estado de salvación, por mano de un regmidor ['redentor'] (2).

gracia $=$ piedad, merced; favor o amor non merecido.

salvación = bienaventuranźa; escapada del pecado y de su pena.

regmidor $=$ uno que paga el precio por un esclavo y lo mete en alforía ['libertad']; un salvador.

${ }^{\left[{ }^{[p . ~ 17] ~}\right.}$ Pre. 21. ¿Quién es el regmidor de los escog̀idos de Dio?

Res. El único regmidor de los escogidos de Dio es el Señor Yešúa el Mašíaḥ ['Jesucristo'] (1), el cual, siendo el eterno hijo de Dio, se hiźo hombre; y ansí era, y continúa de ser Dio y hombre (2), en dos diferentes naturas y en una persona (3) para siempre (4).

Yešúa‘ = salvador: mira Matía 1, 21.

${ }^{17}$ Vid. nota 14; cf. ing. perfect obedience. 
Mašíạ̣ = untado; a saber, con el Espíritu Santo: mira Yeša [yahu] 61, 1.

[p. 19] Pre. 23. ¿Cuáles oficios cumple el Mašíaḥ ['Mesías'] como nuestro regmidor?

Res. El Mašíah, como nuestro regmidor, cumple los oficios de profeta (1), de sacerdote (2) y de rey (3), tanto en su estado de abajamiento como en el de su enšalžamiento.

aḅajamiento = humillación, deshonra.

enšalžamiento $=$ honra, engrandecimiento.

${ }^{[p . ~}{ }^{21]}$ Pre. 25. ¿Cómo cumple el Mašíah el oficio de sacerdote?

Res. El Mašíah cumple el oficio de sacerdote en alźando a sí miśmo una sola veź alźación para contentar la justedad de Dio (1), y afalagarnos con Dio (2), y en haciendo de contino rogativas por nós.

afalagar $=$ meter paź y amistad entre dos personas que estaban antes enemigos.

${ }^{\text {[p. } 25]}$ Pre. 29. ¿Cómo recibimos parte de la regmición ['redención'] comprada por el Mašíạ̣?

Res. Nosotros recibimos parte de la regmición comprada por el Mašíah por medio de la eficiente aplicación ${ }^{18}$ de ella a nosotros (1) por su Espíritu Santo (2).

eficiente $=$ tal que alcanće y cumpla lo que es bušcado.

aplicación $=$ metimiento: un remedio se aplica a un haćino ['enfermo'] .

[p. 26] Pre. 30. ¿Cómo aplica el espíritu a nosotros la regmición comprada por el Mašíaḥ?

Res. El espíritu aplica a nosotros la regmición comprada por el Mašíah en obrando en nosotros la creencia (1) y en ajuntándonos por ella con el Mašíạ̣ en nuestra llamada eficiente (2).

llamada = conviidación.

${ }^{18}$ Vid. nota 14; cf. ing. effectual application. 
[p. 27] Pre. 31. ¿Qué cosa es la llamada eficiente ${ }^{19}$ ?

Res. La llamada eficiente es la obra del espíritu de Dio (1) por la cual, convenciéndonos de nuestro pecado y angustia (2), alunbrando nuestras almas con el conocimiento del Mašíạ (3), y renovando nuestras veluntades (4), él nos sombaye ['convence'] y nos da fuerźa para aḅraźar a Yešúa' el Mašíạ libremente presentado a nosotros en la besorá ['Evangelio'] (5).

convenciéndonos = haciéndonos entender, sentir y atorgar.

renovando $=$ haciendo nuevas y derechas.

aḅraźar = tomar en los braźos, recibir; enfeguciarnos ['confiar'] en Él.

libremente $=$ sin precio; sin demandar de nosotros cosa alguna.

besorá = la anunciación de las buenas nuevas de la salvación.

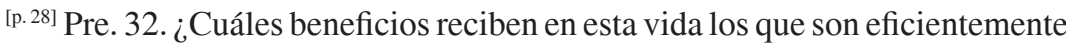
llamados?

Res. Los que son eficientemente llamados reciben en esta vida la justificación (1), el aperfijamiento ['prohijamiento'] (2) y la santificación, y los diferentes beneficios que en esta vida los acompañan o salen de ellos (3).

beneficio $=$ favor, ventaja, bendición .

[p. ${ }^{29]}$ Pre. 33. ¿Qué cosa es la justificación?

Res. La justificación es un hecho de la libre gracia $^{20}$ de Dio por el cual Él nos perdona todos nuestros delitos (1) y nos recibe como $\hat{j} u s t o s$ delantre de Él (2), solamente por cavsa de la derechedad del Mašíạ imputada a nosotros (3) y recibida por la creencia sola (4).

hecho $=$ lo que se hace en un punto.

libre $=$ sin obligación, sin meźcla y sin precio.

imputada a nós = contada como si fuera nuestra propia.

justos $=$ tales que nunca quebraron ${ }^{21}$ de ningún modo la ley de Dio.

${ }^{\text {[p. 30] }}$ Pre. 34. ¿Qué cosa es el aperfijamiento?

${ }^{19}$ Esta es una de las pocas ocasiones en que no se sigue el orden de palabras entre adjetivo y sustantivo del original inglés que se traduce; cf. effectual calling.

${ }^{20}$ Vid. nota 14; cf. ing. free grace.

${ }^{21}$ Corrijo el original puebraros. 
Res. El aperfijamiento es un hecho de la libre gracia de Dio (1) por el cual somos recibidos en el número de los hijos de Dio y tenemos derecho a todos los privileg̀ios que heredan ellos (2).

derecho = título; aquello por lo cual podemos demandar o esperar alguna cosa.

privilegios $=$ honras, favores, beneficios, dados a unos y no a otros.

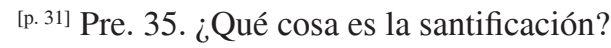

Res. La santificación es la obra de la libre gracia de Dio (1) por la cual somos renovados en el hombre entero según la semejanźa de Dio (2) y recibimos fuerźa para morir más y más al pecado y ỵivir a la derechedad (3).

obra = lo que demanda tiempo para hacerse y se adelanta poco a poco.

el hombre entero $=$ las potencias y los deseos del alma.

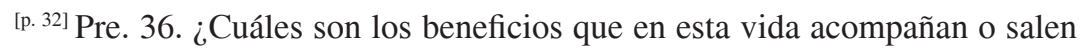
de la justificación, el aperfijamiento y la santificación?

Res. Los beneficios que en esta vida acompañan o salen de la justificación, el aperfijamiento y la santificación son la certeźa del amor de Dio, la paź de la conciencia, el goźo en el Espíritu Santo (1), el acrecimiento en la gracia (2) y la continuación en ella hasta la fin (3).

conciencia $=$ aquella potencia del alma que juźga de nuestros hechos y los apreba o condena.

gracia $=$ conformidad a la semejanźa de Dio.

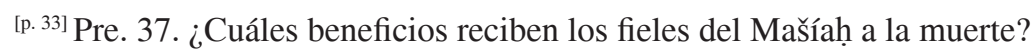

Res. Las almas de los fieles se hacen a la muerte cumplidas en la santidad (1), y pasan en derecho en la honra (2); y sus cuerpos, continuando siempre ajuntados con el Mašíạ (3), reposan en sus fuesas (4) hasta el arreṿivimiento (5).

fieles $=$ los que se enfegucian en Yešúa` el Mašíạ̣ por la salvación.

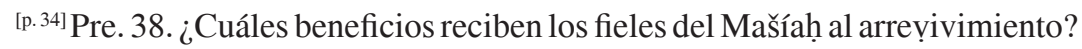

Res. Al arrevivimiento, los fieles, siendo arreṿividos en honra (1), serán abiertamente reconocidos y abssueltos en el día del juicio (2) y se harán enteramente bienaventurados en el cumplido goźamiento de Dio (3) por toda la eternidad. 
reconocidos $=$ atorgados por Dio como sus siervos y amigos.

absueltos = juźgados de no tener culpa alguna.

eternidad $=$ tiempo $\sin$ fin.

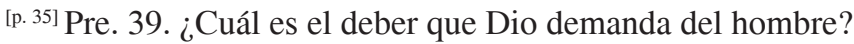

Res. El deber que Dio demanda del hombre es la obediencia a su descubierta veluntad $^{22}(1)$.

descubierta = denunciada, declarada; sea por la conciencia, la creación, la providencia o las Escrituras Santas.

${ }^{[. . .]}$Pre. 40. ¿Qué cosa descubrió Dio en el principio al hombre como la regla de su obediencia?

Res. La regla que Dio en el principio descubrió al hombre para su obediencia era la ley moral (1).

moral $=$ pertenenciente a nuestros deberes, apartando entre lo bueno y lo malo.

[p. ${ }^{\text {36] }}$ Pre. 43. ¿Cuál es la prefación a los dieź mandamientos?

Res. La prefación a los dieź mandamientos es contenida en estas palabras: «Yo soy ${ }^{\left[p .{ }^{37]} H[a s ̌ e m, ~ l i t . ~ ' e l ~ N o m b r e ': ~ ' e l ~ S e n ̃ o r '] ~ t u ~ D i o ~ q u e ~ t e ~ s a q u e ́ ~\right.}{ }^{23}$ de

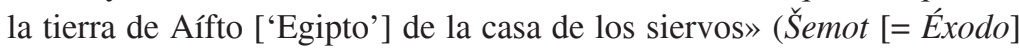
20,2).

prefación = lo que se mete de primero para aparejarnos para lo que viene detrás.

Pre. 44. ¿Qué cosa anỵéźanos la prefación a los dieź mandamientos?

Res. La prefación a los dieź mandamientos anvéźanos que, siendo que H. es el Señor y nuestro Dio y regmidor, por tanto somos obligados a guardar todos sus mandamientos (1).

${ }^{22}$ Vid. nota 14; cf. ing revealed will.

${ }^{23}$ Resulta difícil determinar si en la mente del autor está la forma verbal castellana del perfecto saqué o la judeoespañola saquí -homógrafas en aljamía hebraica (סאקי), toda vez que en la línea anterior estandariza la forma de $1^{a}$ persona del presente de indicativo del verbo ser, y dice soy (a la castellana), en lugar de so (a la sefardí), pero utiliza el eufemismo gráfico ה' para referirse a Dios, habitual en judeoespañol, y usa la forma judeoespañola castiza Aífto, para Egipto. 
Señor = patrón, rey, creador y gobernador del mundo.

Dio $=$ el que merece y tiene derecho de demandar el cumplido entregamiento de nuestros coraźones.

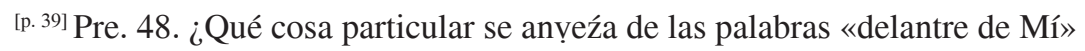
en el primer mandamiento?

Res. Las palabras «delantre de Mí» en el primer mandamiento nos anyeeźan que Dio, que ve toda cosa, nota y se ensaña mucho con el pecado de tener algún otro dio (1).

nota $=$ mira con tino; para mientes sobre alguna cosa .

${ }^{[\ldots .}$ Pre. 50. ¿Qué cosa es demandada en el segundo mandamiento?

Res. El segundo mandamiento demanda que $r e^{[\mathrm{p} .40]}$ cibamos, guardemos y mantengamos limpio y entero todo cualsequier servicio y ordenanźa para su honra (1) que Dio tiene encomendado en su palabra (2).

recibamos $=$ atorguemos que es de con Dio y honremos.

guardemos $=$ hagamos la cosa encomendada.

mantengamos $=$ miremos que ni nosotros miśmos ni otros lo demuden.

ordenanźa = fiesta o otra manera de servicio que debe guardarse de contino en su hora.

${ }^{[\ldots . .]}$ Pre. 51. ¿Qué cosa es vedada en el segundo mandamiento?

Res. El segundo mandamiento nos veda de honrar a Dio por medio de imág̀enes (1) o en cualquier otra manera non encomendada en su palabra (2).

imág̀enes = semejanźas de cualquier cosa, sean de oro, plata, palo, piedra, figuras, vego[mer, lit. 'y concluye'; es decir 'etc.']

${ }^{[\mathrm{p} .}{ }^{41]}$ Pre. 52. ¿Cuáles son las raźones añadidas al segundo mandamiento?

Res. Las raźones añadidas al segundo mandamiento son la soberanidad de Dio sobre nós (1); la propiedad en nós (2), y el ćelo que Él tiene para su propio servicio (3).

raźones $=$ cavsas, argumentos, motivos.

soberanidad = el mayor poder, cumplido y para siempre, como el de un soberano o rey. 
propiedad = el derecho sobre alguna cosa que tiene el que la hiźo, compró o recibió.

ćelo $=$ fuerte amor para alguna cosa y aḅorrición de todo lo que es contrario a ella.

${ }^{[\ldots . .]}$ Pre. 53. ¿Cuál es el tercer mandamiento?

Res. El tercer mandamiento es: «Non jures por el nombre de H. tu Dio a la vanidad ${ }^{\left[{ }^{p}{ }^{42]}\right.}$ porque non libra $\mathrm{H}$. a el que jura por su nombre a la vanidad» (Šemot 20, 7).

a la vanidad $=$ sin cavsa importante.

libra = escusa, justifica, juźga como si no tenía culpa alguna.

Pre. 54. ¿Qué cosa es demandada en el tercer mandamiento?

Res. El tercer mandamiento demanda el santo y temerośo uso de los nombres (1), los títulos (2), los atributos (3), las ordenanźas (4), la palabra (5) y las obras de Dio (6).

nombre = lo que se llama a Dio a cavsa de su natura como «el que es».

título = lo que se llama a Dio a cavsa de lo que es o que hace con sus criaturas, como «el Dio de los fonsados», «el regmidor de Yisrael».

atributos = las propiedades de Dio, como su sabiduría, eternidad, santidad.

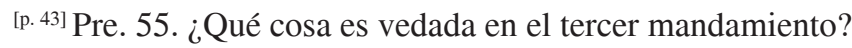

Res. El tercer mandamiento veda todo esyiblamiento ['transgresión'] o abuso de cualquier cosa por la cual Dio se da a conocer (1).

esỵiblamiento $=$ menosprecio o deshonra de alguna cosa santa.

abuso $=$ falso o malo uso.

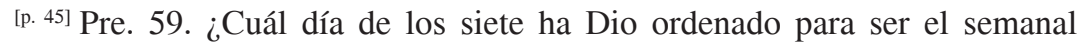
sábado $^{24}$ ?

Res. Desde el principio del mundo hasta el arreỵivimiento del Mašíạ, ordenó Dio el seteno día de la semana para ser el semanal sáḅado (1), y desde aquel tiempo en adelantre el primer día de la semana, el cual debe continuar hasta el fin del mundo, y es el sáḅado cristiano (2).

${ }^{24}$ Vid. nota 14; cf. ing. weekly Sabbath. 
semanal $=$ perteneciente a una semana, aconteciendo cada semana .

${ }^{[\ldots . .]}$ Pre. 60. ¿Qué modo debe el sáḅado ser santificado?

Res. El sábado debe ser santificado por una santa holganźa todo aquel día (1), aun de tales mundanos trabajos y pasatiempos ${ }^{25}$ que en otros días sean licenciados (2); y por entregar todo el tiempo a los públicos y particulares deberes $^{26}$ del servicio de Dio (3), afuera de cuanto tiempo debe ser consumido en obras necesarias ${ }^{27}$ y de la piadad (4).

santificar $=$ apartar para el uso y honra de Dio solo.

mundanos $=$ pertenecientes a este mundo o nuestros oficios .

${ }^{\left[\mathrm{p}{ }^{46}\right]}$ necesarias $=$ tales que sean menesterośas en aquella hora y no pudieran haber sido hechas antes, ni puedan ser atrasadas para después.

${ }^{[\ldots . .]}$ Pre. 61. ¿Qué cosa es vedada en el cuarto mandamiento?

Res. El cuarto mandamiento nos veda la omisión o el descuidadośo cumplimiento $^{28}$ de los deberes demandados (1), y el esviblamiento del día por haraganía (2) o en haciendo lo que por sí miśmo es pecado (3), o por non necesarios pensamientos ${ }^{29}$, palabras o hechos acerca de nuestros mundanos trabajos y pasatiempos (4).

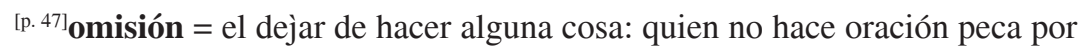
omisión.

descuidadośo $=$ sin cuidado, sin tino, sin paramiento de mientes.

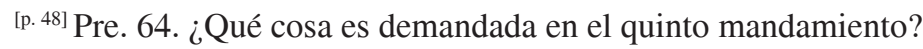

Res. El quinto mandamiento demanda que guardemos la honra y cumplamos los deberes que a cada uno pertenecen en sus particulares grados y relaciones $^{30}$ sean como superiores (1), inferiores (2) o iguales (3).

${ }^{25}$ Vid. nota 14; cf. ing. worldly employments and recreations.

${ }^{26}$ Vid. nota 14; cf. ing. public and private exercises.

${ }^{27}$ Aunque en este caso el adjetivo aparece detrás del sustantivo -frente a lo que venimos señalando- bien puede deberse a que la frase que se traduce dice realmente works of necessity and mercy.

${ }^{28}$ Vid. nota 14; cf. ing. careless performance.

${ }^{29}$ Vid. nota 14; cf. ing. unnecessary thoughts.

${ }^{30}$ Vid. nota 14; cf. ing. their several places and relations. 
grados = estados de vida como rey, jueź, pačhá, mayoral, viejo, sabio, vego. relaciones $=$ ataduras como las de marido y mujer, padre y hijo, maestro $\mathrm{y}$ siervo, rey y súbdito, vecinos uno con otro, y de todos los hombres uno con otro.

superiores $=$ los que están en un más alto grado que nosotros.

inferiores $=$ los que están en un más bajo grado que nosotros.

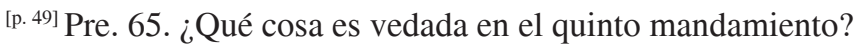

Res. El quinto mandamiento nos veda el descuido o cualsequier quebrantamiento del honor y del deber que pertenecen a cada uno en sus diferentes grados y relaciones (1).

descuido = mengua de atención para hacer alguna cosa como se debe.

${ }^{[\ldots .]}$ Pre. 66. ¿Cuál es la raźón añadida al quinto mandamiento?

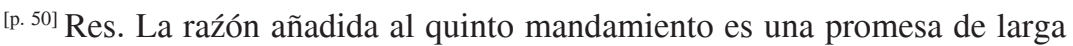
vida $^{31}$ y de prosperidad (en cuanto serviría para la honra de Dio y para el propio bien de ellos) a todos los que guardan este mandamiento (1).

prosperidad $=$ riqueźa, honra, alto grado, vego.

[...] Pre. 68. ¿Qué cosa es demandada en el sešeno mandamiento?

Res. El sešeno mandamiento nos demanda todos los esfuerźos licenciados para guardar nuestra propia vida (1) y la vida de los otros (2).

esfuerźos = el uso de todo nuestro poder y enĝeño para alcanźar cualquier cosa.

licenciado $=$ justo, según la ley ${ }^{32} ;$ lo que Dio nos deja hacer.

[p. 51] Pre. 69. ¿Qué cosa es vedada en el sešeno mandamiento?

Res. El sešeno mandamiento nos veda quitar nuestra propia vida (1) o la vida de nuestro compañero injustamente (2), o cualsequier cosa que pueda cavsar esto (3).

inĵustamente $=$ por tortura, falsedad o fuerźa; contra justedad .

\footnotetext{
${ }^{31}$ Vid. nota 14; cf. ing. long life.

${ }^{32}$ Tal es la puntuación del original, que separa con coma justo y según la ley.
} 


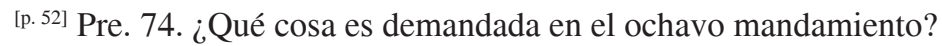

Res. El ochavo mandamiento demanda el jus ${ }^{[\mathrm{p} .}{ }^{53}{ }^{53}$ o procuramiento ${ }^{33} \mathrm{y}$ muchiguamiento de la riqueźa y hacienda tanto de nosotros miśmos (1) como de los otros (2).

hacienda = toda manera de bienes y posesiones.

${ }^{\left[{ }^{[. .]}\right.}$Pre. 75. ¿Qué cosa es vedada en el ochavo mandamiento?

Res. El ochavo mandamiento veda todo lo que disminuye $e^{34}$ o puede disminuir injustamente la riqueźa o hacienda de nosotros miśmos (1) o de nuestro compañero (2).

disminuye $=$ apoca, hace menor, gasta.

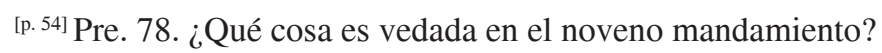

Res. El noveno mandamiento veda cualsequier cosa [que] sea perjudicial a la verdad (1), o dañośa a nuestra propia buena fama (2) o a la de nuestro compañero (3).

perjudicial $=$ tal que detenga la verdad de ser conocida o que haga que la verdad no sea recibida y estimada.

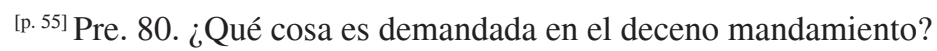

Res. El deceno mandamiento demanda entero contento ${ }^{35}$ con nuestro propio estado (1), a_una con un justo y amistośo espíritu escuentra nuestro compañero y todo lo que es suyo (2).

contento $=$ el recibir con gusto y agradecimiento lo que Dio nos da, sin desear ansiosamente otras cosas.

[p. ${ }^{\text {56] }}$ Pre. 81. ¿Qué cosa es vedada en el deceno mandamiento?

Res. El deceno mandamiento veda todo descontento con nuestro propio estado (1), ćelar o atristarnos sobre el bien de nuestro compañero (2), y todos desreglados deseos y amores ${ }^{36}$ por alguna cosa que pertenece a él (3).

\footnotetext{
${ }^{33}$ Vid. nota 14; cf. ing. the lawful procuring.

34 alj. דיסמינוייאי.

${ }^{35}$ Vid. nota 14; cf. ing. full contentment.

${ }^{36}$ Vid. nota 14; cf. ing. all inordinate motions and affections.
} 
desreglados $=$ non sujeftados a la regla o ley de Dio, ni tampoco a la de nuestra propia conciencia, tales que se apoderen de nuestras almas.

[p. ${ }^{\text {57] }}$ Pre. 83. ¿Son igualmente aborrecibles todos los quebrantamientos de la Ley?

Res. Algunos pecados por si miśmos y a cavsa de modos de agravamientos son más aḅorrecibles que otros en los ojos de Dio (1).

agravamientos $=$ cosas que hacen una culpa más pesada.

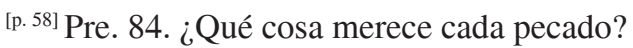

Res. Cada pecado merece el folor y la maldición de Dio, tanto en esta vida como en la venidera (1).

folor = la santa, infinita, inmudable saña de Dio, y el castigo por el cual ella se muestra.

maldición = la santa denunciación y metimiento de su folor.

${ }^{[\ldots . .]}$ Pre. 85. ¿Qué cosa demanda H. de nosotros para escapar de su folor y maldición, los que por el pecado merecemos?

Res. Para escapar del folor y de la maldición de Dio, los que por el pecado merecemos, H. demanda de nosotros la creencia en Yešúa' el Mašíạ̣ (1), el arrepentimiento para la vida eterna (2) a_una con el dilig̀ente uso de todos los esteriores medios por los cuales el Mašíạ̣ reparte a nosotros los beneficios de la regmición (3).

diligente = cuidadośo; tal que muestre que amamos y deseamos lo que decimos que estamos bušcando.

esteriores $=$ los de afuera; llamados ansí para apartarlos de la interior o secreta obra del Espíritu Santo sobre el coraźón.

medios = aquellas cosas de las cuales nos servimos para alcanźar algún fin.

[p. ${ }^{59]}$ Pre. 86. ¿Qué cosa es la creencia en Yešúa' el Mašíaḥ?

Res. La creencia en Yešúa' el Mašíah es una gracia salvante (1) por la cual lo recibimos y nos reposamos sobre Él a sus solas para la salvación, como Él está enpresentado a nosotros en la besorá (2).

gracia $=$ toda cosa que el Espíritu Santo obra en el coraźón. 
salvante $=$ eficiente; tal que siempre acompañe ${ }^{37}$ la salvación.

recibimos = tomamos como una dádiva a los pecadores; atorgamos que estamos contentos [sic] con justamente un tal Salvador.

nos reposamos $=$ nos enfeguciamos con certeźa y paź, sin alguna duda o espanto, en las promesas del Mašíạ̣.

[p. ${ }^{60]}$ Pre. 87. ¿Qué cosa es el arrepentimiento para vida?

Res. El arrepentimiento para vida es una gracia salvante (1) por la cual un pecador, movido de un verdadero sentimiento ${ }^{38}$ de sus pecados (2) y convencido de la merced de Dio en el Mašíah (3), con dolor y aborrecimiento de su pecado, se torna de él a Dio (4) intentando con coraźón cumplido nueva obediencia y es ${ }^{[p .61]}$ forźándose para alcanźarla (5).

verdadero sentimiento vego. $=$ justo juicio de la muchedumbre, grandeźa y aḅorrecible natura de sus pecados.

intentando $=$ teniendo el deseo y intención de hacer alguna cosa.

con coraźón cumplido = sin engaño, sin escusar el más chico pecado.

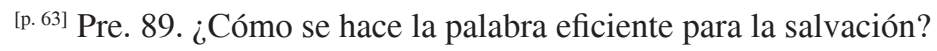

Res. El espíritu de Dio hace el meldamiento ['lectura'], ma particularmente el darsamiento ['prédica'], de la palabra un eficiente medio para convencer y convertir a los pecadores (1), y para enfortecerlos en la santidad y el conhortamiento (2) por la creencia, para la salvación (3).

convencer $=$ traerlos a entender y sentir su culpa y su peligro debajo de la maldición del Dio Santo.

convertir $=$ sombayir a una persona con justas raźones, a que se torne de su descreencia y de todos sus pecados, y crea en el Mašíạ por la salvación.

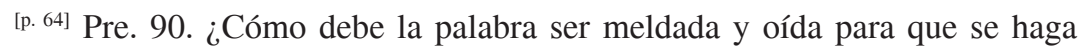
eficiente para la salvación?

Res. Para que la palabra se haga eficiente para la salvación, debemos entregarnos a ella con dilig̀encia (1), aparejamiento (2) y oración (3); recibirla con creencia y amor (4); atresorarla en nuestros coraźones (5), y quitarla en hecho en nuestras vidas (6).

\footnotetext{
${ }^{37}$ alj. אקומפאנייאי.

${ }^{38}$ Vid. nota 14; cf. ing. true sense.
} 
dilig̀encia $=$ cuidado; paramiento de mientes para aprovecharnos.

${ }^{[p .}{ }^{65]}$ Pre. 91. ¿Cómo se hacen los sacramentos eficientes medios de la salvación ${ }^{39}$ ?

Res. Los sacramentos se hacen eficientes medios de la salvación, no a cavsa de virtud alguna que haiga en ellos o en el que los administra (1), sino solamente por la bendición del Mašíạ y la obra de su espíritu en aquellos que los reciben con creencia (2).

virtud = fuerźa o poder, valor o merecimiento.

administra $=$ reparte , con el derecho de uno que fuere ordenado para esto.

[p. ${ }^{6]}$ Pre. 92. ¿Qué cosa es un sacramento?

Res. Un sacramento es una santa ordenanźa ordenada por el Mašíạ, en la cual, por señales sensibles, el Mašíạ y los beneficios del nuevo firmamiento son representados, sellados y aplicados a los creyentes (1).

el sacramento era entre los romanos la jura de obediencia y fieldad que dieron los soldados a sus capitanes.

señales $=$ cosas de que nos servimos para dar a entender otras cosas, sean sonidos, pensamientos, personas, acontecimientos, vego.

sensibles $=$ tales que se puedan conocer por los cinco sentidos: ver, oír, tocar, goler, gustar.

representados $=$ presentados o metidos delantre de nosotros otra veź; quiere decir, non en derecho sino en figura, y por señales ordenados y conocidos.

sellados $=$ como si fueran asegurados a los creyentes con la escritura, firma y sello del Mašíạ̣.

aplicados $=$ empresentados ['regalados'], metidos en la mano como una dádiva.

${ }^{[p .67]}$ Pre. 94. ¿Qué cosa es el baftismo?

Res. El baftismo es un sacramento en el cual el lavar con agua en el nombre del Padre, del Hijo y del Espíritu Santo (1) representa y sella nuestro metimiento en el Mašíă y nuestra participación en los beneficios del firmamiento de gracia (2), y nuestra promesa de ser para el Señor (3).

${ }^{39}$ Vid. nota 14; cf. ing. effectual means of salvation. 
metimiento $=$ como el de un ramo estraño en un árbol ${ }^{40}$.

participación $=$ recibimiento de una parte de alguna cosa.

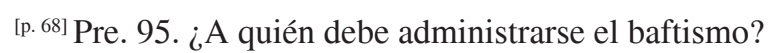

Res. El baftismo no se debe administrar a ninguno que esté fuera de la iglesia visible, hasta que no hubiere atorgado su creencia en el Mašíạ y su obediencia a Él (1); ma las criaturas de aquellos que son miembros de la iglesia visible, deben ser baftiźados (2).

iglesia = la compaña de aquellos que tienen y atorgan la creencia del Mašíah y guardan sus ordenanźas.

visible $=$ la que se ve de los hombres y en la cual puede haber engañadores, porque Dio solo conoce los coraźones.

${ }^{[\cdots . .]}$ Pre. 96. ¿Qué cosa es la cena del Señor?

Res. La cena del Señor es un sacramento en el cual, por el dar y recibir pan y vino según el ordenamiento del Mašíạ, se manifiesta su muerte (1); y los merecidos recibidores se hacen non en una cor $^{\left[\mathrm{p} .{ }^{69]}\right.}$ poral y carnal manera $^{41}$ sino por la creencia, participantes de la carne y de la sangre de Él con todos sus beneficios, para su espiritual sustento ${ }^{42}$ y acrecimiento en la gracia (2).

se manifiesta $=$ se anuncia; se da a saber a todos los al-derredor.

merecidos = tales que son conṿidados; a saber, los verdaderos dičípulos.

corporal y carnal = perteneciente al cuerpo y a la carne; quiere decir, que no comen el miśmo cuerpo ni beben la miśma sangre del Mašíạ̣, como creen los católicos.

espiritual $=$ perteneciente al espíritu o alma.

${ }^{[\ldots . .]}$ Pre. 97. ¿Qué cosa es demandada para el merecido recibimiento ${ }^{43}$ de la cena del Señor?

\footnotetext{
${ }^{40}$ A tenor de la definición dada, la forma metimiento equivale aquí a 'injerto', paralelo del ing. ingrafting que se traduce, frente al uso que tenía más arriba (29), como sinónimo de aplicación.

${ }^{41}$ Vid. nota 14; cf. ing. corporal and carnal manner.

${ }^{42}$ Vid. nota 14; cf. ing. spiritual nourishment.

${ }^{43}$ Vid. nota 14; cf. ing. worthy receiving.
} 
Res. De los que quieren recibir merecidamente la cena del Señor, se demanda que se preben a sí miśmos en cuanto a su conocimiento para dicernir el cuerpo del Señor (1); a su creencia para sostenerse de Él; su arrepentimiento (3), amor (4) y nueva obediencia (5); de miedo que ${ }^{44}$, viniendo sin derecho, no coman y beban condenación para sí miśmos (6).

${ }^{[p .70]}$ dicernir $=$ apartar; entender la diferencia entre una cosa y otra; distinguir

[...] Pre. 98. ¿Qué cosa es la oración?

Res. La oración es el endereźamiento de nuestros deseos a Dio (1), por cosas agradables a su veluntad (2) en el nombre del Mašíạ (3), con atorgamiento de nuestros delitos (4) y agradecido reconocimiento ${ }^{45}$ de sus mercedes (5).

agradecido $=$ lleno de amor por favores recibidos.

${ }^{\left[{ }^{[p} .11\right.}$ reconocimiento $=$ enmentamiento, recontamiento de alguna cosa; el no callarla o olvidarse de ella.

${ }^{[. . .]}$Pre. 99. ¿Cuál regla nos ha dado Dio para endereźarnos en la oración?

Res. La entera palabra de Dio es de uso para endereźarnos en la oración (1), ma la particular regla para nuestro endereźamiento es aquella forma de oración la cual el Mašíạ̣ anỵeźó a sus dičípulos, llamada ordinariamente «la oración del Señor» ${ }^{46}(2)$.

endereźar = anṿeźar; amostrar cómo y cuáles cosas debemos demandar.

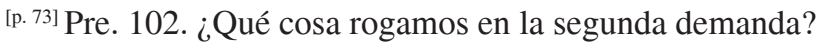

Res. En la segunda demanda (que es «venga tu reino») rogamos que el reino de Satán sea destruido (1) y que el reino de la gracia sea adelantado (2): que nosotros miśmos y otros seamos traídos dentro de él y guardados en él (3), y que el reino de la honra sea apresurado.

el reino de Satán = el poder por el cual el Diablo lleva engañadas y cautivadas las almas de los hombres a su propia deperdición.

${ }^{44}$ Traduce el ing. lest 'por miedo a que; para que no; no sea que'.

${ }^{45}$ Vid. nota 14; cf. ing. thankful acknowledgment.

${ }^{46}$ Vid. nota 11. 
el reino de la gracia $=$ el poder que el Mašíạ tiene por su espíritu es este mundo, en todos aquellos que reciben su gracia.

el reino de la honra $=$ el poder que tendrá Dio para siempre sobre todos los salvados pecadores a_una con los ánĝeles, vego.: el estado de la honra de siempre después del juicio postrero.

${ }^{[p .}{ }^{75]}$ Pre. 105. ¿Qué cosa rogamos en la quinta demanda?

Res. En la quinta demanda (que es «y perdónanos nuestras devdas, ansí como nosotros también perdonamos a nuestros devdores») rogamos que Dio, por amor del Mašíah, nos perdone libremente todos nuestros pecados (1); lo que somos tanto más esforźados para rogar, porque por su gracia podemos del coraźón perdonar a los otros (2).

devdas = toda manera de pecado.

nuestros devdores $=$ los que pecaron contra nosotros.

esforźados = llamados de fegucia ['fiucia, confianza'].

[p. 76] Pre. 106. ¿Qué cosa rogamos en la sešena demanda?

Res. En la sešena demanda (que es «y no nos traigas en preba, ma escápanos del malo») rogamos que Dio, o no nos deje ser prebados para pecado (1), o que nos asufra ['sostenga'] y escape ['salve'] en siendo prebados (2).

preba $=$ tal estado en el cual algún provecho parece ajuntado con el pecado, y nuestro apetito malo despierta en nós deseos de pecar.

${ }^{[\ldots . .]}$ Pre. 107. ¿Qué cosa anỵéźanos la terminación de la oración del Señor?

Res. La terminación de la oración del Señor (que es «porque tuyo es el reino, la barraganía ['poder'] y la hermosura para siempre, amén») anỵé[p. 77] źanos a que tomemos de Dio solo nuestro esforźo en la oración (1), y que en nuestras oraciones lo alabemos atriḅyéndole el reino, la barraganía y la honra (2); y que en testimonio de nuestro deseo o certeźa de ser escuchados, digamos «amén» (3).

atribuyéndole $=$ atorgando que pertenecen a Él solo.

amén = cierto, firme, que sea ansí. 


\section{ESTUDIO LINGÜÍSTICO}

David Bunis (1992: 411) define la lengua de las publicaciones de las misiones protestantes como una especie de «pseudo-Sephardi vernacular (essentially a blend of Old and Modern Spanish transcribed in the Hebrew alphabet)» y tal es más o menos lo que encontramos en nuestro texto. Ahora bien, más que una mezcla de español antiguo y moderno -salvo que entendamos aquél en relación al léxico de textos como la Biblia de Ferrara u otros ladinamientos bíblicos-, el judeoespañol de los textos publicados por los protestantes se me antoja el resultado híbrido de una especie de «español sefardizado»; cuál sea el peso relativo del modelo hispano decimonónico o el de la adaptación a la singularidad judeoespañola, está todavía por determinar.

\subsection{Grafías}

Desde un punto de vista gráfico, y a pesar de que como hemos dicho, el texto está escrito en aljamía hebraica, en el Catecismo hay claros indicios para pensar que es el español peninsular decimonónico el que mayoritariamente se trasluce en sus páginas. Así, la grafía hispánica normativa de una forma determinará en muchos casos su escritura aljamiada en el texto judeoespañol: por regla general, si esta se escribe con $<\mathrm{j}>\mathrm{o}<\mathrm{g}>$ intervocálicas en español, llevará źayin con tilde $\left\langle{ }^{\prime} \uparrow\right.$ en el Catecismo -independientemente de si en judeoespañol presenta o no la palatal fricativa sonora $-{ }^{47}$, mientras que si lleva $<j>0<\mathrm{g}>$ en posición inicial o tras consonante, se escribirá con guímal con tilde $\langle$ 'ג>; y si se escribe con $\langle\mathrm{Z}\rangle$ en español, aparecerá siempre con źayin $\langle i>$, llevando sámej $\langle\nabla\rangle$, si en español normativo presenta $<\mathrm{s}>\mathrm{O}<\mathrm{c}\rangle^{48}$.

${ }^{47}$ El mismo fenómeno exhibía la forma lujo glosada en La hermośa Hulda de España (Constantinopla, 1910), escrita con źayin con tilde y no con šin, como le correspondería por evolución fonética (García Moreno 2010: 80)

${ }^{48}$ Esta regla general sólo parece incumplirse en nuestro texto en el caso de ćelo (alj. זילו), pero lo cierto es que los diccionarios españoles de la época recogían habitualmente zelo. Si nos fijamos en el DRAE, hasta la edición de 1837, zelo aparece como entrada principal y celo como secundaria; en las ediciones de 1843 y 1852 ambas formas aparecen como entradas principales; en la de 1869, zelo pasa a ser entrada secundaria de celo, y sólo a 
Este hecho resulta especialmente llamativo cuando la forma en cuestión está documentada desde antiguo en judeoespañol con otra grafía, como sucede $\operatorname{con}^{49}$ : abajamiento / אבאז'אמיינט (23), y no abajamiento /

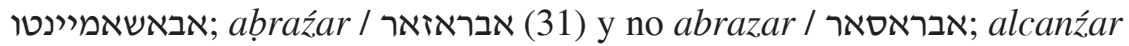

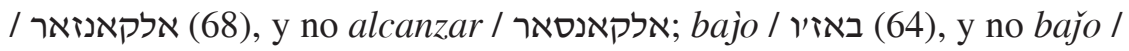

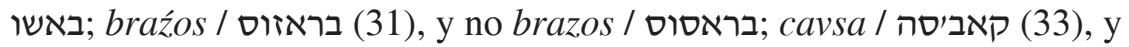

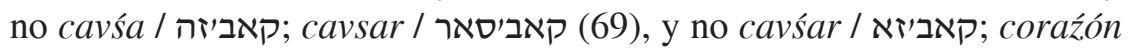

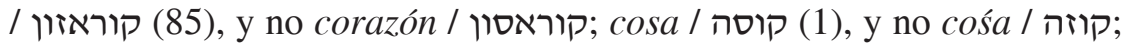

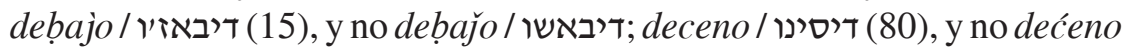

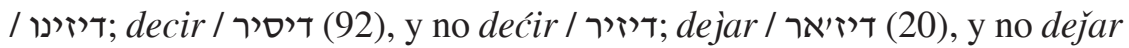

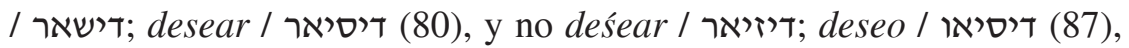

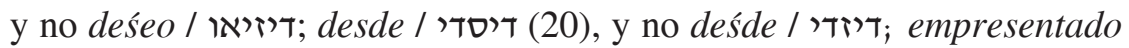

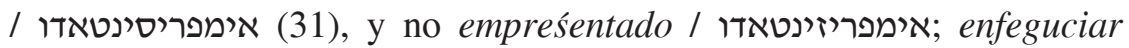

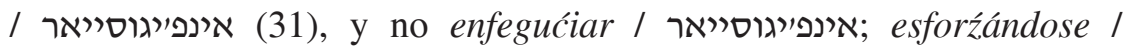

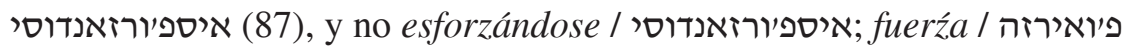

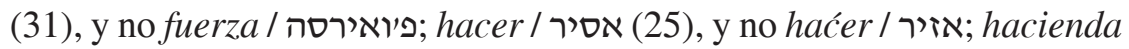

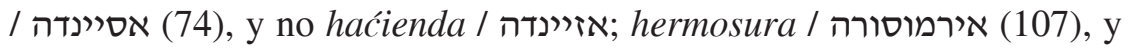

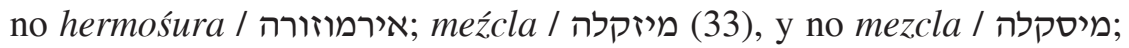

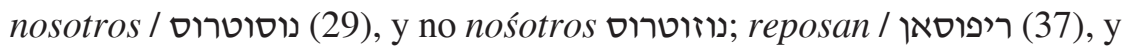

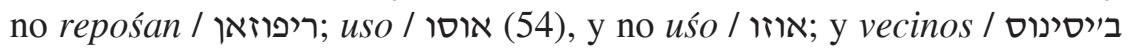
(64), y no većinos / בייזינוס.

Es más, en aquellos casos en los que no se da tal disparidad, como en principal (alj. פרינסיפאל) o raźones (alj. ראזוניס), por citar algunos, cabe incluso la posibilidad de que la escritura aljamiada acorde con la tradición sefardí sea mera coincidencia.

Ahora bien, no es cierto que la grafía (y su equivalencia fonética) de nuestro texto esté totalmente mediatizada por la norma gráfica latina del español contemporáneo. Baste con señalar cómo en formas como ajuntamiento / אג'ונטאמיינטו, el carácter derivado de la palabra hace que en judeoespañol se mantenga en posición intervocálica el fonema palatal africado sonoro /d’z/ inicial de la base, y así nos lo muestra su grafía con guímal (no źayin) con tilde.

partir de la edición de 1884 se incluye únicamente celo. Por otro lado, no podemos obviar la posible influencia gráfica de la forma inglesa zeal, que recoge y define Watts (1745).

${ }^{49}$ Ordenadas alfabéticamente, remitimos entre paréntesis al número de pregunta del Catecismo en que se da la primera ocurrencia; introducimos únicamente el infinitivo de los verbos y el singular de los sustantivos, cuando se documentan en el texto. 


\subsection{Léxico}

En el plano del léxico -que con frecuencia (Quintana 1999: 595) se cita para mostrar lo que podríamos llamar contaminación castellana del judeoespañol de los misioneros protestantes- resulta difícil determinar si en nuestro texto es mayor el trasvase de neologismos desde el español contemporáneo, o si predominan los casos en que Thomson buscó la forma judeoespañola más castiza para traducir el original inglés.

Si nos centramos en las entradas del vocabulario, cierto es que exceptuando un puñado de formas castizas que no pertenecen al estándar peninsular como afalagar, enšalžamiento, esyiblamiento, firmamiento, folor, preba y regmidor -lo mismo que los hebraísmos amén (hb. אמן), besorá (hb. בשורה 'noticia', aquí para referirse al Evangelio), Mašíah (hb. משיח 'ungido, Mesías'), Satán (hb. שטן) y Yešúa' (hb. ישוע 'Jesús') muchas de las formas podrían estar tomadas del español contemporáneo, aun sin ser exclusivas de este, y como prueba de ello podrían aducirse precisamente todos los casos reseñados supra de lo que entendemos como «aljamías a la española». Asimismo, la forma contentos muestra claramente su origen peninsular, frente al contentes habitual en judeoespañol.

Ahora bien, no debemos olvidar que ciertos ejemplos de formas y usos más o menos perdidos en el judeoespañol vernáculo de la época y mantenidos en el estándar peninsular, pueden documentarse en los ladinamientos bíblicos -y de ahí su conocimiento y utilización por parte de los misioneros ${ }^{51}-$, con lo que realmente estaríamos ante ejemplos de revitalización de arcaísmos del judeoespañol. Tal sería el caso de criaturas, que tiene en judeoespañol el valor de 'niños, bebés', ${ }^{52}$ y

${ }^{50}$ Aunque no como entrada, en la respuesta 19 encontramos también guehinam (hb. 'Infierno') y frecuentemente aparece la forma abreviada vego[mer] (hb. 'וגהינם).

${ }^{51}$ De hecho en el catálogo de la biblioteca de la British and Foreign Bible Society, publicado pocos años después que el Catecismo, constan copias de distintas ediciones de la Biblia en Lengua Española traduzida palabra por palabra de la verdad Hebrayca... (Bullen 1857: 75), junto con las versiones judeoespañolas de la Biblia de Yisrael Bajar Hayim y de William Schauffler (Bullen 1857:70), e incluso un par de traducciones del Nuevo Testamento al judeoespañol (BULLEN 1857: 138).

52 Así, en CherezliDic (p. 221) leemos criatura 'enfant' frente a crianza 'créature' y lo mismo sucede en NehamaDict (p. 309): bajo kriánsa leemos 'étre vivant', y bajo kriatura 'nourrisson, enfant en bas âge'. 
que se define en el Catecismo como «todas las cosas yivas»: sentido correspondiente al de su valor como término religioso en español, y con el que, por ejemplo, se documenta en La Biblia de Ferrara.

Asimismo, al igual que en otros textos sefardíes modernos no es difícil encontrar voces tomadas de lenguas romances como el francés o el italiano que, tras sufrir cierta adaptación morfonológica al judeoespañol, podrían pasar por préstamos del español cuando no lo son, en el caso de textos de las misiones protestantes como este, la adaptación fónica al judeoespañol de modernos hispanismos, los puede estar haciendo pasar a nuestros ojos por formas castizas seculares, cuando a lo mejor estamos ante su primera documentación en judeoespañol. Tal es lo que entendemos que puede estar sucediendo con dicernir (esp. discernir) y esteriores (esp. exteriores), en los que los grupos consonánticos han sido reducidos como es general en judeoespañol, si no es que nuevamente estamos ante más arcaísmos, ya que español antiguo documentamos diçernir y esteriores, respectivamente ${ }^{53}$.

Por último, en ciertos casos vemos cómo las formas explicadas en el Catecismo corresponden a neologismos surgidos del calco de la forma inglesa que se traduce, como en soberanidad (52), a partir del ing. sovereignty, y en otras ocasiones encontramos una especie de híbridos. Tal es lo que sucede con el uso de la forma judeoespañola castiza Dio (y no Dios como en español) pero sin el artículo que normalmente la acompaña, o con el carácter oclusivo de la [b] de sáḅado, por influjo de la forma šaḅat (hb. שבת).

\subsection{Características del vocabulario}

El carácter de glosario (y no de diccionario, propiamente dicho) del conjunto de todas estas aclaraciones se deja sentir con más fuerza en lo que respecta a los lemas, entendiendo como tales aquellos segmentos de texto que se pretende aclarar, pues estos se consignan tal cual aparecen en la respuesta. Así, por ejemplo, las formas nominales aparecen indistintamente en masculino, femenino, singular o plural, según los casos; también encontramos sustantivos precedidos de artículo o seguidos de adyacentes, $\mathrm{y}$ al lado de infinitivos, aparecen formas verbales flexionadas o con pronombres clíticos.

\footnotetext{
${ }^{53}$ Apud CORDE, consultado el 2 de agosto de 2012.
} 
Aunque es verdad que la forma del lema prefigura muchas veces la redacción de la explicación (con sinónimos en plural para lemas en plural, o mediante paráfrasis con el verbo en la misma forma que aquella que se quiere aclarar, etc.), y sin perder de vista que la aclaración de formas o formulaciones viene muchas veces determinada por su aparición en el contexto doctrinal concreto del catecismo ${ }^{54}$, lo cierto es que encontramos no pocos casos en que la explicación dada en judeoespañol bien podría corresponder a la definición de cualquier diccionario al uso de la época, por más que no se siga ninguno en particular ${ }^{55}$, ni se traduzcan las aclaraciones de Watts (1745). Tal es lo que sucede, por recordar algunos, con sustantivos como:

aḅuso = falso o malo uso;

eternidad = tiempo sin fin;

fin = una cosa bušcada y deseada;

firmamiento $=$ trato entre dos o más personas;

hacienda = toda manera de bienes y posesiones;

hecho = lo que se hace en un punto;

obra = lo que demanda tiempo para hacerse y se adelanta poco a poco;

providencia $=$ la potencia de ver de avante lo que acontecerá; goberno, reg̀imiento;

raźones $=$ cavsas, argumentos, motivos;

adjetivos, como:

espiritual $=$ perteneciente al espíritu o alma;

inmudable = que no se puede demudar;

${ }^{54}$ Así sucede especialmente con: atributos, atribuyéndole, besorá, contento, convencer, convertir, desreglados, devdas, (nuestros) devdores, Dio, esviblamiento, fieles, folor, gracia, iglesia, justos, maldición, Mašíah, merecidos, nombre, perjudicial, preba, recibamos, recibimos, reconocidos, (el) reino de la gracia, (el) reino de la honra, (el) reino de Satán, nos reposamos, salvación, salvante, santificar, sellados, (verdadero) sentimiento, Señor, título, visible y Yešúa:

${ }^{55}$ Así se desprende de una cala en el NTLLE (2001), con especial atención a los diccionarios bilingües de Stevens y de Neuman-Baretti, allí incluidos. Precisamente de este último, se reseñan ejemplares en el catálogo de la biblioteca de la British and Foreign Bible Society (BULLEN 1857: 205 y 272). 
necesarias $=$ tales que sean menesterośas en aquella hora y no pudieran haber sido hechas antes, ni puedan ser atrasadas para después;

semanal $=$ perteneciente a una semana; aconteciendo cada semana;

adverbios, como:

inĵustamente $=$ por tortura, falsedad o fuerźa; contra justedad;

formas verbales, como:

dicernir = apartar; entender la diferencia entre una cosa y otra; distinguir;

disminuye $=$ apoca, hace menor, gasta .

intentando $=$ teniendo el deseo y intención de hacer alguna cosa.

y aun con la interjección

amén = cierto, firme, que sea ansí.

Como es habitual en la llamada lexicografía precientífica, no faltan casos en los que la aclaración del lema se lleva a cabo mediante la referencia a su uso pragmático, como vemos en:

aplicación = metimiento: un remedio se aplica a un haćino;

o se acompaña de ejemplos, como en:

grados = estados de vida como rey, jueź, pačhá, mayoral, viejo, sabio, vego.;

relaciones $=$ ataduras como las de marido y mujer, padre y hijo, maestro y siervo, rey y súbudito, vecinos uno con otro, y de todos los hombres uno con otro.

En nuestro texto, a menudo se recurre a un uso impersonal de las formas (verbales, adjetivales y pronominales) de $1^{\mathrm{a}}$ persona (la cursiva es mía):

derecho $=$ título, aquello por lo cual podemos demandar o esperar alguna cosa;

esfuerźos = el uso de todo nuestro poder y enĝeño para alcanźar cualquier cosa;

medios = aquellas cosas de las cuales nos servimos para alcanźar algún fin;

mundanos $=$ pertenecientes a este mundo o nuestros oficios;

representados $=$ presentados o metidos delantre de nosotros otra veź; quiere dećir, non en derecho sino en figura y por señales ordenados y conocidos; 
señales $=$ cosas de que nos servimos para dar a entender otras cosas, sean sonidos, pensamientos, personas, acontecimientos, vego.

En algún caso se presenta una definición etimológica como en:

Mašíạ̣ = untado; a saber, con el Espíritu Santo;

y hasta encontramos definiciones de tipo enciclopédico, como en el singular caso de sacramentos, donde falta la general distinción tipográfica entre entrada y definición:

el sacramento era entre los romanos la jura de obediencia y fieldad que dieron los soldados a sus capitanes;

o como en la última porción de la explicación de:

sensibles $=$ tales que se puedan conocer por los cinco sentidos: ver, oír, tocar, goler, gustar.

Y en varios ejemplos -abraźar, (con) corazón cumplido, corporal y carnal, descubierta, esteriores, licenciado y omisión- la explicación dada es doble: la primera tiene carácter general, y la segunda guarda relación con el contexto catequético en que aparece la forma en cuestión. Veámoslo con:

aḅraźar = tomar en los braźos, recibir; enfeguciarnos en Él [=Yešúa', el Mašíah].

Y es que, aun con la vista puesta en la captación de acólitos o en la formación de los nuevos catecúmenos, el Catecismo da muestra de un alarde metalingüístico que, en judeoespañol, era prácticamente desconocido hasta entonces.

\section{Conclusiones}

Volviendo sobre el interrogante que da título a este estudio, podemos concluir que en el Catecismo, aunque disperso, se localiza el primer ejemplo monolingüe reconocible de la lexicografía sefardí.

Aunque mediatizado tanto por las fuentes de que su autor, Alexander Thomson, se sirvió, como por la intención evangelizadora última de su composición, el Catecismo contiene lo más parecido a un diccionario que 
durante muchos años habían producido las letras sefardíes en judeoespañol.

Es la lengua del texto un judeoespañol muy singular que a veces se nos antoja casi español aljamiado, pero que no estaba más alejado del vernáculo que la lengua de los ladinamientos bíblicos, o que la expresión de los textos modernos más afrancesados; y lo que es más importante, es un judeoespañol que por primera vez se utiliza, con conciencia lexicográfica, para explicarse a sí mismo. 


\section{BiBLIOGRAFÍA}

Edwin Musell BuIss et al. (1904 [1891]). The encyclopedia of missions: Descriptive, historical, biographical, statistical. New York, Funk \& Wagnalls, $2^{\mathrm{a}}$ ed.

Leah Bornstein-Makovetsky (1996). פעילות המיסיון האמריקאי בקרבג יהודי אסתאמבול, איזמיר ושלוניקי במאה התשע-עשרה (19, en Minna RozEN (ed.): The Days of the Crescent: Chapters in the History of the Jews in the Ottoman Empire. Tel Aviv University, The Chair for the History and Culture of the Jews of Salonika and Greece, The Diaspora Research Institute, 273-310.

- (2002). «Jewish Converts to Islam and Christianity in the Ottoman Empire in the Nineteenth Century», en Minna Rozen (ed.): The Last Ottoman Century and Beyond: The Jews in Turkey and the Balkans 1808-1945. Tel Aviv University, The Goldstein-Goren Diaspora Research Center, The Chair for the History and Culture of the Jews of Salonika and Greece, vol. II, 83-127.

George Bullen (1857). Catalogue of the Library of the British and Foreign Bible Society. London, Reed and Pardon.

David Bunis (1992). «The Language of the Sephardim: A Historical Overview», en Haim BeInART (ed.): Moreshet Sepharad: The Sephardi Legacy. Jerusalem, The Magnes Press-The Hebrew University, vol. II, 399-422.

- (2002). «Rabbi Yehuda Alkalay and his Linguistic Concerns», en Z. HARver et al. (eds.), Zion and Zionism among Sephardic and Eastern Jews. Jerusalem, Misgav Yerushalayim, pp. 155-212. En hebreo.

— (2011). «Judezmo Glossaries and Dictionaries by Native Speakers and the Language Ideologies behind Them», en Winfried Busse y Michael Studemund-Halévy (eds.): Lexicología y lexicografía judeoespañolas. Bern (et al.), Peter Lang, 339-431.

CherezliDic $=$ Salomon Israel Cherezli $/$ Šelomó Yisrael ŠEREŚLí, Nouveau Petit Dictionnaire Judeo-Espagnol-Français / Nuevo chico diccionario judeo-español-francés (Jerusalén, 1898-99).

CORDE $=$ Real ACAdEmia Española, Banco de datos (CORDE) [en línea]. Corpus diacrónico del español. <http://www.rae.es>. 
DRAE $=$ REAL ACADEMIA EsPañola, Diccionario de la Lengua Española . Aitor García Moreno (2004). Relatos del pueblo ladinán: Me'am lo'eź de Éxodo. Madrid, CSIC.

- (2010). «Glosas frescas en La hermośa Hulda de España (Jerusalén, 1910)», en Paloma DíAz-MAs y María SÁnchez PÉrez (eds.): Los sefardies ante los retos del mundo contemporáneo. Identidad y mentalidades. Madrid, CSIC, 75-85.

Iacob M. Hassán (1978). «Transcripción normalizada de textos judeoespañoles», Estudios Sefardíes 1, 147-150.

Heinrich KoHRING (2011). «Lexicographica judaeohispanica. Florilegium», en Winfried Busse y Michael Studemund-Halévy (eds.): Lexicología y lexicografía judeoespañolas. Bern (et al.), Peter Lang, 287-337.

Missionary Review (1899). = The Missionary Review of the World, 22.

NehamaDict = Joseph NeHAma (1977). Dictionnaire du judéo-espagnol. Avec la collaboration de Jesús Cantera. Madrid, CSIC.

NTLLE (2001) = REAL ACADEMIA EsPAÑOLA, Nuevo Tesoro Lexicográfico de la Lengua Española. Edición en DVD-ROM. Madrid, EspasaCalpe.

Proceedings $(1854)=$ Proceedings of the General Assembly of the Free Church of Scotland held at Edinburgh, May 1854. Appendix $N^{o} I$ : Report on Foreign Missions. Edinburgh, John Greig \& Son - Glasgow, Glass and Duncan - London, James Nisbet and Co.

- $(1855)=$ Proceedings of the General Assembly of the Free Church of Scotland held at Edinburgh, May 1855. Appendix $N^{o}$ I (Proceedings, 1st June 1855): Report on Foreign Missions. Edinburgh, John Greig \& Son - London, J. Nisbet and Co.

Aldina Quintana (1999). «Proceso de recastellanización del judesmo», en Judit Targarona Borrás y Ángel Sáenz Badillos (eds.): Jewish Studies at the turn of the Twentieth Century. Leiden-Boston-Köln, Brill, 593-602.

- (2013). «Israel bar Hayim de Belogrado, the "Write as you speak" principle and the nomenclature in the Sefer Otsar Hahayim (1823)», ParDes - Zeitschrift der Vereinigung für Jüdische Studien e. V., 19, 35-55.

Elena RoMero (1992). La creación literaria en lengua sefardí. Madrid, Mapfre. 
- (2010). «La polémica sobre el judeoespañol en la prensa sefardí del Imperio otomano: más materiales para su estudio», Sefarad 70, 435473.

Isaac WATTs (1745). The Assembly's Catechism with Notes, or the Shorter Catechism composed by the Assembly of Divines at Westminster: with A brief Explication of the more difficult Words and Phrases contained in it, for the Instruction of Youth. $6^{\text {th }}$ Edition, London, James Brackstone.

Recibido: 10/11/2012

Aceptado: 09/09/2013 